\title{
Articular and periarticular spinal calcifications in relation to synovial fluid findings in patients with calcium pyrophosphate dihydrate deposition disease (CPPD)
}

Mohamed Ismail Abdelkareem', Abdou Saad Taha Ellabban², Ahmed Hamed Ismail²,

Mohamed Moneer Rayan ${ }^{1}$ and Rasha Ali Abdel-Magied ${ }^{2^{*}}$ (D)

\begin{abstract}
Background: Calcium pyrophosphate dihydrate deposition disease (CPPD) is the second most common form of the crystal-associated arthritis. Diagnosis is achieved by detection of crystals by polarized light microscopy and/or detection of hyaline cartilage or fibrocartilage calcifications characteristic of CPPD deposition by musculoskeletal ultrasound (MSUS). Axial involvement with intervertebral disc calcification, sacroiliac erosions, and sub-chondral cysts of the facet joints occurs with CPPD deposition.

Aim: To assess the presence and relation between calcification of intervertebral discs, other articular and periarticular spinal structures, and synovial fluid analysis (SFA) and MSUS calcifications in patients with CPPD deposition disease.
\end{abstract}

Methods: One hundred patients with CPPD disease diagnosed according to the modified proposed diagnostic criteria by McCarty 1994 were included. Plain radiography on the spines, pelvis, and affected joints, MSUS on affected joints, and synovial fluid analysis (SFA) were done.

(Continued on next page)

\footnotetext{
* Correspondence: rashahazem@yahoo.com

${ }^{2}$ Rheumatology and Rehabilitation Department, Minia University, Minia, Egypt

Full list of author information is available at the end of the article
}

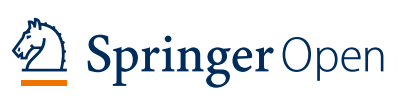

(๑) The Author(s). 2021 Open Access This article is licensed under a Creative Commons Attribution 4.0 International License, which permits use, sharing, adaptation, distribution and reproduction in any medium or format, as long as you give appropriate credit to the original author(s) and the source, provide a link to the Creative Commons licence, and indicate if changes were made. The images or other third party material in this article are included in the article's Creative Commons licence, unless indicated otherwise in a credit line to the material. If material is not included in the article's Creative Commons licence and your intended use is not permitted by statutory regulation or exceeds the permitted use, you will need to obtain permission directly from the copyright holder. To view a copy of this licence, visit http://creativecommons.org/licenses/by/4.0/. 
(Continued from previous page)

Results: Spinal calcification was present in 55\% of patients. The commonest site was anterior longitudinal ligament (43\%). Characteristic CPPD calcifications by plain radiography on the knee and wrist joints were present in 38\% and 16\% respectively. Characteristic CPPD calcifications by MSUS on the knee and wrist joints presented in $93 \%$ and $27 \%$ respectively. CPPD crystal detection by SFA was $97 \%$. The accuracy of MSUS to diagnose CPPD deposition disease is more than double that of plain radiography, and it is comparable to that of synovial fluid analysis. The result of intra-rater analysis between SFA by polarized light microscopy and MSUS was kappa 0.767 ( $p<0.001)$; this indicates substantial level of agreement between SFA and MSUS; between plain radiography and MSUS, it was kappa 0.188 ( $p=0.32)$ which indicates slight agreement, and between plain radiography and SFA, it was kappa $0.037(p=0.1)$ which fails to reach a significant level of agreement. There was a significant positive relation between spinal calcification and wrist joint calcification by plain radiography.

Conclusion: Considerable spinal affection by CPPD deposition disease can be detected. Although the most definitive, reliable direct approach for CPPD deposition disease diagnosis is SFA using polarized light microscopy, MSUS is considered a useful non-invasive diagnostic tool in this situation. In CPPD deposition disease, MSUS has proven to be an excellent technique for detecting calcification in the articular tissue disease compared to conventional radiography.

Keywords: Calcium pyrophosphate dihydrate deposition disease (CPPD), Musculoskeletal ultrasound, Spinal calcification, Synovial fluid analysis

\section{Background}

Calcium pyrophosphate dihydrate deposition (CPPD) disease is common in which CPPD crystals deposit within the joint leading to calcification [1-3]. McCarty and co-workers first identified CPPD crystals [4]. The crystals were found in the synovial fluid of patients without sodium urate crystals who had gout-like symptoms. This phenomenon was later described as "pseudogout" and radiologically defined by prominent multifocal calcifications in the articular cartilages and intervertebral disc spaces [5].

The CPPD crystals are observed to have weaker birefringence using polarized light microscopy as opposed to the stronger birefringence of mono-sodium urate (MSU) crystals. Radiographical diffraction or electron probe analysis best determines the exact nature of these crystals [6]. The gold standard for diagnosis of CPPD deposition disease is the identification of CPPD crystals using the compensated polarized light microscopic examination of the synovial fluid in the absence of joint infection or other cause of arthritis, particularly for acute conditions [7, 8].

High-frequency musculoskeletal ultrasound (MSUS) has been shown to be an outstanding tool for the accurate assessment of articular and juxta-articular changes and calcific deposits in crystal-induced diseases. MSUS is a sensitive and specific method in the evaluation of patients with chondrocalcinosis [3, 9].

Axial involvement with intervertebral disc calcification, sacroiliac erosions, and sub-chondral cysts of the facet joints occurs with CPPD deposition disease [10]. CPPD deposits within the ligamentum flavum or the transverse ligament of the atlas can be sizable and can progress, causing cervical canal stenosis, cervical myelopathy, and foramen magnum syndrome. Odontoid fracture due to the calcification of the atlantoaxial joint may occur in CPPD deposition disease [11].

The aim of this study was to assess the presence and relation between calcification of intervertebral discs, other articular and periarticular spinal structures, and synovial fluid analysis findings and musculoskeletal ultrasound calcifications in patient with CPPD.

\section{Methods}

Study design: cross-sectional observational study

One hundred patients diagnosed as CPD crystal deposition disease according to the modified proposed diagnostic criteria by McCarty 1994 [12, 13] from outpatient clinics of rheumatology, with knee effusion candidate for aspiration, were included. The exclusion criteria are as follows: autoimmune disease, diabetic patients, renal osteodystrophy, hypothyroidism, hyperparathyroidism, hypervitaminosis D, idiopathic hypercalcemia, hemochromatosis, and diffuse idiopathic skeletal hyperostosis. All patients had, through clinical examination, plain radiography for the spines (antero-posterior and lateral views), wrist joints (anteroposterior view), and knee joints (antero-posterior view), searching for punctate and linear radiodensities in intervertebral discs, fibrocartilage, and hyaline or articular cartilage and calcification of spinal ligaments.

Conventional gray-scale ultrasound was performed using a $10-18-\mathrm{MHz}$ linear scanner and middle-class to high-end machine ultrasound device (ACUSON X700 Ultrasound System - Siemens, America). Examination was carried out for the knee and wrist joints bilaterally 
both longitudinal and transverse scans on cartilage (hyaline cartilage of the femoral condyles) and fibrocartilage (triangular fibrocartilage of the wrist and meniscus) searching for CPPD deposits ultrasonographically. CPPD deposits are hyperechoic that present in various patterns: pattern I, thin hyperechoic bands parallel to the surface of the hyaline cartilage; pattern II "punctate pattern," consisting of multiple thin hyperechoic spots; and pattern III, homogeneous nodular or oval hyperechoic deposits, mostly mobile, found in bursae and articular recesses [14]. Synovial fluid analysis was done for all patients using polarized light microscopy for detection of CPPD crystals by an expert. The same operator performed the MSUS and SF analysis.

\section{Statistical analysis}

The data was analyzed using the statistical package for the social sciences program (SPSS Inc., Chicago, IL, USA) version 16.0. Categorical and quantitative variables were respectively defined as numbers/percentage (\%) and mean $\pm \mathrm{SD}$. The Mann-Whitney or chi-square $\left(X^{2}\right)$ tests compared variables. The intra-rater reliability (single rater and two replications) was assessed using the kappa coefficient of Cohen. A kappa value $0.01-0.20$ was considered slight agreement, $0.21-0.40$ fair agreement, 0.41-0.60 moderate agreement, $0.61-0.80$ substantial agreement, and 0.81-0.99 almost perfect agreement. The statistical significance level was set at a $p$ level lower than 0.05 . Sensitivity and specificity of plain radiography and musculoskeletal ultrasonography for the detection of calcification were calculated using the formula:

$$
\begin{aligned}
& \text { Sensitivity }=\frac{\text { Diseased persons with positive test }}{\text { All diseased persons }} \times 100 \\
& \text { Specificity }=\frac{\text { Non diseased persons with negative test }}{\text { All non }- \text { diseased persons }} \times 100
\end{aligned}
$$

\section{Results}

Out of the 100 patients with CPPD deposition disease included in the study, 42 were males $(42 \%)$ and 58 were females (58\%); their age ranged from 43 to 80 years with a mean of $62.2 \pm 4.5$ years; and disease duration ranged from 0.1 to 12 years with a mean of $14.5 \pm 3.1$ years.

Table 1 Characters of CPPD deposition disease patients, plain radiography, and MSUS detection of calcifications and synovial fluid

\begin{tabular}{|c|c|c|}
\hline \multicolumn{2}{|c|}{ Parameter mean \pm SD and/or $n(\%)$} & \multirow{2}{*}{$\begin{array}{l}\text { CPPD patients } \boldsymbol{n}=\mathbf{1 0 0} \\
62.2 \pm 4.5\end{array}$} \\
\hline Age (years) & & \\
\hline Gender $\mathrm{F}$ to $\mathrm{M}$ & & $58: 42$ \\
\hline Disease duration (years) & & $14.5 \pm 3.1$ \\
\hline \multirow[t]{7}{*}{ Plain radiography } & Spinal calcification & $55(55)$ \\
\hline & Intervertebral disc calcification & $16(16)$ \\
\hline & Anterior longitudinal ligament & $43(43)$ \\
\hline & Posterior longitudinal ligament & $20(20) 3(3)$ \\
\hline & Ligamentum flavum & $38(38)$ \\
\hline & Knee calcification & $16(16)$ \\
\hline & Wrist calcification & \\
\hline \multirow[t]{10}{*}{ Musculoskeletal ultrasound } & Knee calcification & $93(93)$ \\
\hline & Pattern of calcification & \\
\hline & Pattern I & $55(55)$ \\
\hline & Pattern ॥ & $67(67)$ \\
\hline & Pattern III & $10(10)$ \\
\hline & Wrist calcification & $27(27)$ \\
\hline & Pattern of calcification & \\
\hline & Pattern I & $3(3)$ \\
\hline & Pattern ॥ & $26(26)$ \\
\hline & Pattern III & 0 \\
\hline \multicolumn{2}{|c|}{ Synovial fluid finding of CPPD crystals } & (97) \\
\hline
\end{tabular}
finding of CPPD crystals in studied group

On conventional radiography, spinal calcification was found in 55 patients (55\%); the commonest site was anterior longitudinal ligament (43\%), posterior longitudinal ligament (20\%), intervertebral disc (16\%), and ligamentum flavum (3\%). Meniscal calcification was found in 38 patients (38\%); triangular fibrocartilage calcifications of the wrist were found in 16 patients (16\%)

MSUS showed CPPD calcifications in the menisci, femoral hyaline cartilage, and bursae and articular recesses in the knee joint in 93 patients (93\%) and in the triangular fibrocartilage of the wrist in 27 patients (27\%)

Three patients out of 100 patients (3\%); CPPD crystals could not be detected by synovial fluid analysis by polarized light microscopy, but could be shown by MSUS 
Characteristic features of CPPD crystal deposition disease patients are presented in Table 1 . On conventional radiography, spinal calcification was found in 55 patients (55\%) (Fig. 1a); the commonest site of spinal calcification in studied CPPD deposition disease patients were anterior longitudinal ligament (43\%) followed by posterior longitudinal ligament (20\%), intervertebral disc (16\%), and lastly ligamentum flavum (3\%); and it was noticed that more than one site of calcification was found in some patients. Meniscal calcification was found in 38 patients (38\%) (Fig. 1b), and triangular fibrocartilage calcifications of the wrist were found in 16 patients $(16 \%)$ (Table 1). MSUS examination showed that CPPD calcifications characteristic of CPPD deposition was found in the menisci, femoral hyaline cartilage, and bursae and articular recesses in the knee joint in 93 patients (93\%) and in the triangular fibrocartilage of the wrist in $27 \mathrm{pa}-$ tients (27\%). The commonest pattern of knee joint calcification in the studied CPPD deposition disease patients was pattern II in 62 patients (67\%) (Fig. 2) followed by pattern I in 51 patients (55\%) (Fig. 3) and lastly pattern III in 9 patients (10\%). More than one site of calcification was found in some patients. In the wrist joint, the commonest type was pattern II in 26 patients $(26 \%)$ then pattern I in 3 patients (3\%) (Fig. 3) (Table 1).

It was found that in three patients out of 100 patients (3\%), CPPD crystals could not be detected by synovial fluid analysis by polarized light microscopy, but could be shown by MSUS. CPPD crystals by polarized microscopy are shown in Fig. 4.

Figure 5 presents the percent of the diagnosis of CPPD deposition disease by synovial fluid analysis, MSUS, and conventional plain radiography. The accuracy of MSUS to diagnose CPPD deposition disease is more than

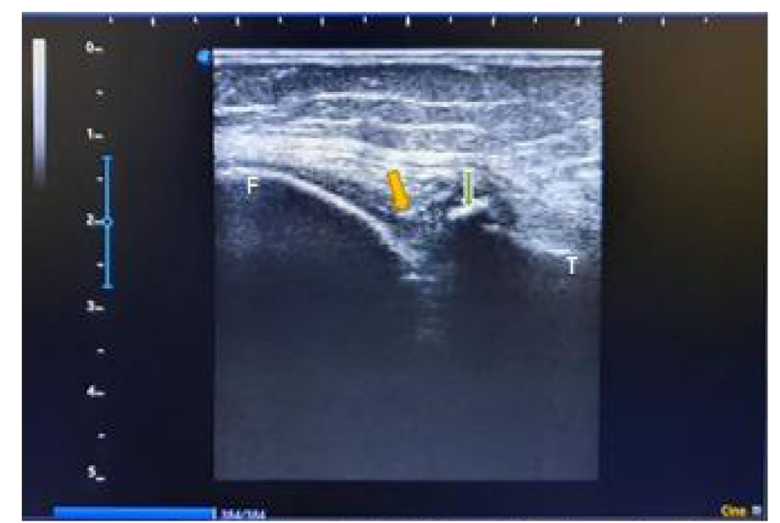

Fig. 2 MSUS; longitudinal scan shows several thin hyperechoic spots in the fibrocartilage of right medial meniscus or punctate pattern (pattern II) in the right knee joint characteristic of CPPD deposition. Knee, lateral longitudinal scan showing distal femur (F) and proximal tibia (T) with hyperechoic CPPD deposits embedded in the substance of the lateral meniscus (yellow arrow) and large osteophyte (green arrow)

double that of conventional radiography, and it is comparable to that of synovial fluid analysis.

In patients with CPPD crystals, the sensitivity of MSUS for calcification detection was $95.8 \%$ while that of conventional radiography was $39.2 \%$, while the specificity was $100 \%$ for both MSUS and conventional radiography for calcification detection.

In three of the cases, CPPD crystals could not be detected by synovial fluid analysis by polarized light microscopy, but MSUS showed characteristic features of CPPD crystal deposition disease.

The result of intra-rater analysis between SFA by polarized light microscopy and MSUS for detection of CPPD calcification was kappa $0.767(p<0.001)$; this
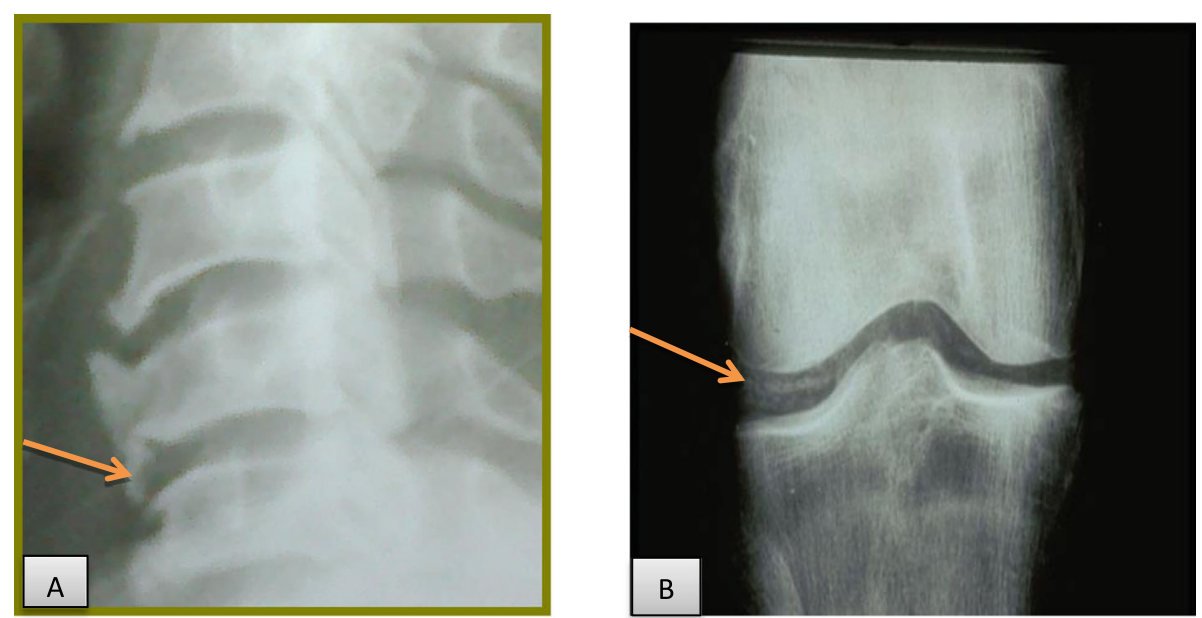

Fig. 1 a Plain X-ray, lateral view of on cervical spine shows anterior longitudinal ligament calcification (arrow). b Plain radiography of the knee joint showing chondrocalcinosis (arrow) 


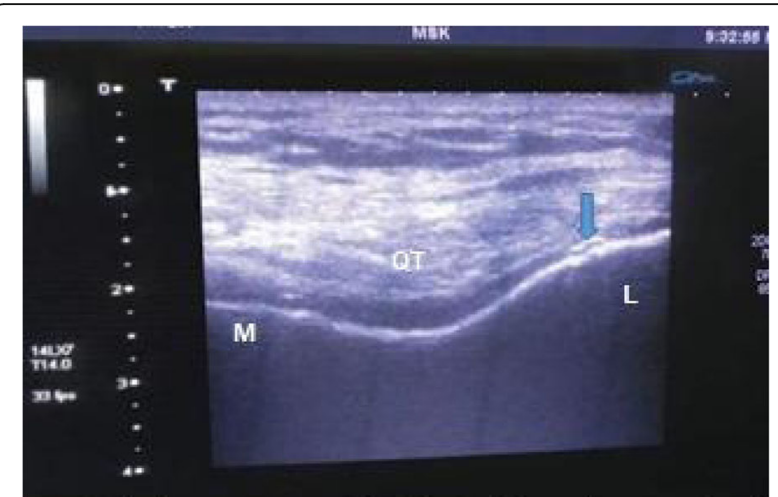

Fig. 3 MSUS; transverse scan shows thin hyperechoic band parallel to the surface of the hyaline cartilage (pattern I) in the femoral condyle characteristic of CPPD deposition. Knee, suprapatellar transverse scan in full flexion. Convex bony contour of femoral condyle is the deepest structure. A bright, hyperechoic band of CPPD deposition (arrow) is seen embedded in the dark, anechoic to hypoechoic hyaline cartilage that covers the femoral condyle. L, lateral; $\mathrm{M}$, medial; TQ, quadriceps tendon

indicates substantial level of agreement between SFA and MSUS; however, between conventional radiography and MSUS, it was kappa $0.188(p=0.32)$ which indicates slight agreement, and between conventional radiography and SFA, it was kappa $0.037(p=0.1)$ which fails to reach a significant level of agreement.

Table 2 presents the relation between the presence of spinal calcification in patients with CPPD deposition disease and the presence of calcifications characteristic of CPPD deposition in the knee and wrist joints detected by conventional plain radiography and MSUS. There was a significant positive association between spinal calcification and wrist joint calcifications by conventional radiography.

\section{Discussion}

The second most common type of the crystal-induced arthritis is detected as calcium pyrophosphate dihydrate deposition disease [10]. The clinical presentation of CPPD can vary from asymptomatic to acute or chronic inflammatory arthritis, with a variety of symptoms and signs similar to those seen in cases of gout or other forms of inflammatory arthritis or septic arthritis making it difficult to distinguish clinically between CPPD disease and other joint-affecting conditions. About $25 \%$ of patients presented with acute pseudogout, rheumatoid-like appearance accounts for less than $5 \%$ of patients with CPPD disease, and more than $50 \%$ of patients with CPPD disease have symptoms like osteoarthritis [15-18]. In those who develop arthritis symptoms, physical examination has little value in the diagnosis and its consequences $[8,19]$.

Diagnosis is confirmed by using polarized microscopy and the identification of crystals in the synovial fluid [7] or the detection of the characteristic calcification of CPPD crystal deposition (chondrocalcinosis) in the conventional plain radiography and/or high-resolution MSUS to detect hyaline articular cartilage or fibrocartilage calcifications [8]. Axial involvement with intervertebral disc calcification, sacroiliac erosions, and subchondral cysts of the facet joints occurs with CPPD deposition disease [10].

In our study, we found that incomplete spinal calcification was present in 55 patients (55\%) of all patients. It was higher than that noticed by Salaffi and co-workers [20] where conventional radiographs showed spinal calcifications in 17 patients (34.7\%), but their study was done on the cervical spine only (conventional radiographs of the upper cervical spine only were performed), other spine regions were not examined, patients had a higher age (range 66-88, mean age $70.4 \pm 6.8$ years) in comparison to our study. On the contrary, the study of Sekijima and co-workers [21] showed that $100 \%$ of fourteen patients had cervical spine calcifications; this difference may be related to the older age of patients included in their study (range 54 to 92 with mean \pm SD, $77.5 \pm$
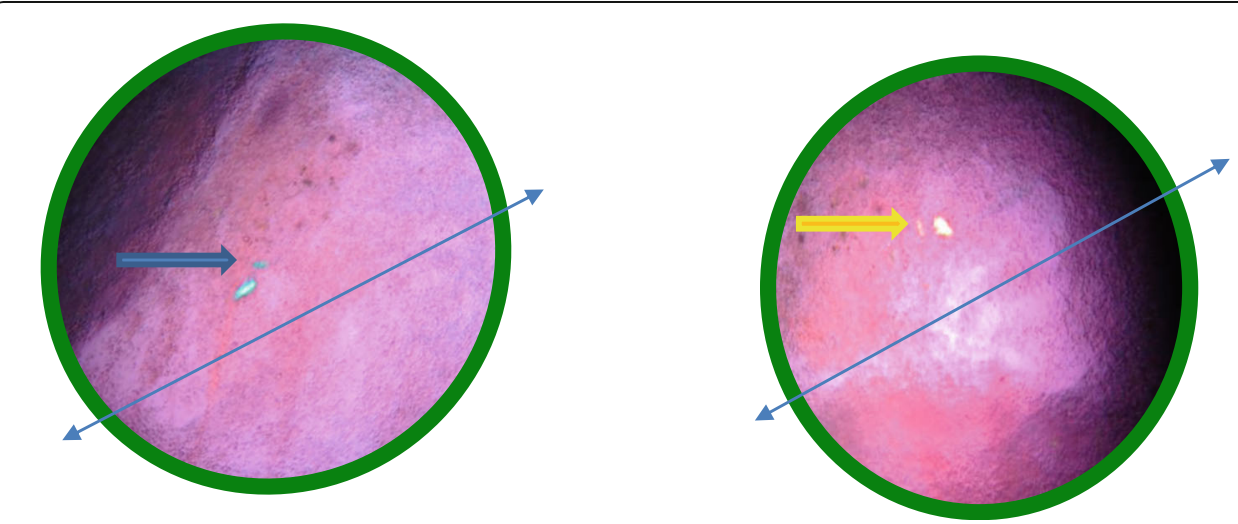

Fig. 4 CPPD crystals by polarized microscopy. Rhomboid-shaped positively birefringent crystal (blue when oriented parallel to the axis of the compensator (blue arrow) and yellow when perpendicular to the axis of the compensator (yellow arrow)) (magnification $\times 40$ ) 


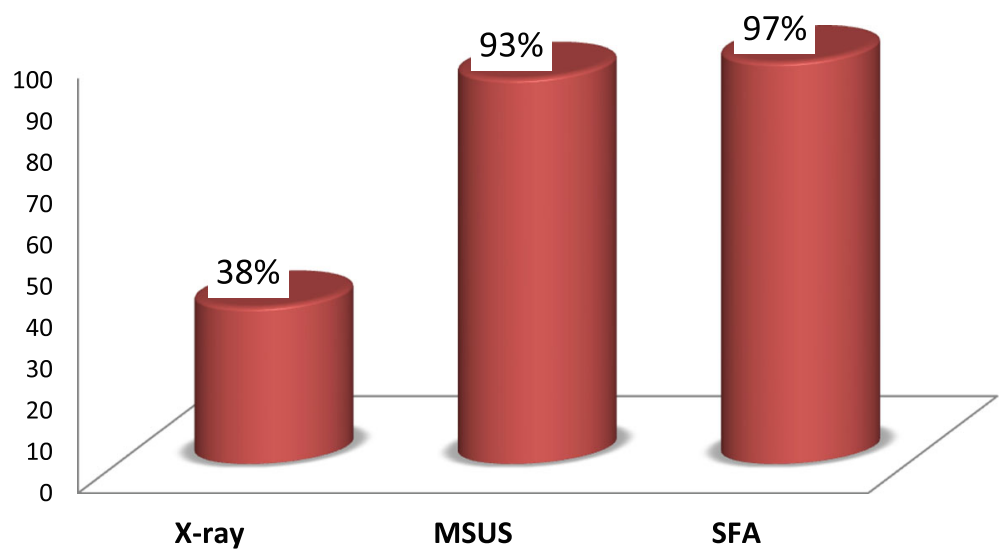

Fig. 5 Percent of the diagnosis of CPPD deposition by conventional plain radiography, MSUS and synovial fluid analysis. The accuracy of MSUS to diagnose CPPD calcification is more than double that of X-ray, and it is comparable to that of synovial fluid analysis

8.5). Moreover, computed tomography was used, not conventional radiography as in our study, and their study was done on the cervical spines only. Our values are also lower than the research done by Finckh and coworkers [22] where cervical calcifications were found in 24 out of 35 patients (69\%) in the CPPD based on computed tomography beside conventional radiography.

Chondrocalcinosis (intervertebral disc calcification) was noted in 16 patients (16\%) in our study, in agreement with results of the study done by Gruber and coworkers [23], which was based on histologic features with special attention to crystal deposition of intervertebral disc (cervical, lumbar, and lumbosacral); they showed that $14.69 \%$ (31out of 211 patients) of the specimens were positive for the presence of crystals, although this is histological study, but the mean age was lower than that of our study, which was $35 \pm 11.8$ years. Also, in the study population of Berlemann co-workers [24], the histopathological study of postoperative degenerated lumbar discs showed that CPPD crystal deposition was found in $15.7 \%$ of the investigated patients $(12.6 \%$ of discs).

In our study, comparison between MSUS and SFA to diagnose CPPD deposition disease showed that MSUS diagnoses CPPD deposition disease in the joint in 93 patients (93\%) which was higher than that noticed by Foldes [25], which was $89 \%$, but the studied patients in this research was small in number (21 patients against 100 in our study); also, the transducer frequency used was $5-10 \mathrm{MHz}$, whereas in our study, it was $10-18$ $\mathrm{MHz}$.

In the current study, the sensitivity of ultrasonography for detection of calcification in patients with CPPD crystals was $95.8 \%$ while that of plain radiography was $39.2 \%$. In the study done by Filippou and co-workers [26], the sensitivity of MSUS to diagnose CPPD deposition disease was $96.4 \%$. In the study by Ellabban et al. [18], they found that the MSUS sensitivity was $84.2 \%$ for the detection of CPPD calcification, while it was $13 \%$ for conventional radiography. In their study, sixty patients

Table 2 Relation between the presence of spinal calcification and the presence of calcifications characteristic of CPPD deposition in the knee and wrist joints detected by conventional radiography and MSUS in the studied patients

\begin{tabular}{|c|c|c|c|c|c|c|}
\hline & \multirow[t]{2}{*}{ Calcification } & & \multicolumn{2}{|c|}{ Spinal calcification } & \multirow[t]{2}{*}{$x^{2}$} & \multirow[t]{2}{*}{$p$} \\
\hline & & & Present $n(\%)$ & Absent $n(\%)$ & & \\
\hline \multirow[t]{4}{*}{ Plain X-ray } & Knee & Present & $20(37)$ & $18(40)$ & 0.091 & 0.763 \\
\hline & & Absent & $35(63)$ & $27(60)$ & & \\
\hline & Wrist & Present & $13(24.1)$ & $3(6.7)$ & 5.489 & 0.019 \\
\hline & & Absent & $42(75.9)$ & $42(93.3)$ & & \\
\hline \multirow[t]{4}{*}{ MSUS } & Knee & Present & $51(92.6)$ & $42(93.3)$ & 0.002 & 0.866 \\
\hline & & Absent & $4(7.4)$ & $3(6.7)$ & & \\
\hline & Wrist & Present & $18(31.5)$ & $9(20)$ & 1.671 & 0.196 \\
\hline & & Absent & $37(68.5)$ & $36(80)$ & & \\
\hline
\end{tabular}

There was significant positive association between spinal calcification and wrist joint calcifications detected by conventional radiography 
with knee effusion were included; their age ranged from 25 to 70 years with a mean of $49 \pm 9.3$ years; searching for the presence of CPPD crystals, they found CPPD crystals in synovial fluid in 32/60 patients (53.3\%), and they had also calcification characteristic of CPPD in MSUS evaluation; however, plain radiographic calcification characteristic of CPPD was found only in 5 patients with ultrasonically defined CPPD calcifications knee joint. The difference from the current study may be due to the small number of CPPD patients included in their study (32 patients versus 100); also, the transducer frequency used was $7.5-12 \mathrm{MHz}$, whereas we used a higher transducer frequency $(10-18 \mathrm{MHz})$.

The presence of CPPD crystals in synovial fluid certainly confirm the diagnosis, based on standard diagnostic criteria for CPPD crystal deposition disease, but a negative microscopic test does not preclude it $[12,13]$.

\section{Conclusions}

Considerable spinal affection by CPPD deposition disease can be detected. Although the most definitive, reliable direct approach for CPPD deposition disease diagnosis is SFA using polarized light microscopy, MSUS is considered a useful non-invasive diagnostic tool in this situation. In CPPD deposition disease, MSUS has proven to be an excellent technique for detecting calcification in the articular tissue disease compared to conventional radiography.

\section{Strength of the study}

The strength of the study is as follows: three cases, in which CPPD crystals could not be detected in synovial fluid by polarized light microscopy, but MSUS showed characteristic features of CPPD crystal deposition disease (probable diagnosis) which raises the diagnostic value of MSUS and so reflects the importance of use of MSUS in diagnosing CPPD deposition disease.

\section{Limitations of the study}

The limitations of the study are as follows: the small number of the studied population, not considering other causes of calcification other than CPPD deposition disease, and not considering the presence of other types of crystals. The MSUS is time consuming when searching for every site for calcification.

\section{Abbreviations \\ CPPD deposition disease: Calcium pyrophosphate dihydrate deposition disease; MSUS: Musculoskeletal ultrasound; SFA: Synovial fluid analysis}

\section{Acknowledgements}

Not applicable.

\section{Authors' contributions}

MIA, ASE, AHI, MMR, and RAA prepared the study design. RAA and AHI contributed to the data acquisition and analyzed and interpreted the patient data. RAA performed the synovial fluid analysis and musculoskeletal ultrasound and was a major contributor in writing the manuscript. All authors have read and approved the manuscript

\section{Funding}

This research did not receive any specific grant from funding agencies in the public, commercial, or not-for-profit sectors.

\section{Availability of data and materials}

The datasets used and/or analyzed during the current study are available from the corresponding author on reasonable request.

Ethics approval and consent to participate

This study is a thesis and is an extension of my previous published study in Rheumatology International.

Consent for publication

Not applicable.

\section{Competing interests}

The authors declare that they have no competing interests.

\section{Author details}

${ }^{1}$ Physical Medicine and Rehabilitation Department, Al-Azhar University, Assuit, Egypt. ${ }^{2}$ Rheumatology and Rehabilitation Department, Minia University, Minia, Egypt.

Received: 29 September 2020 Accepted: 23 December 2020

Published online: 13 January 2021

\section{References}

1. Beyeler C (2002) Calcium pyrophosphate deposits-a chameleon. Ther Umsch 59(10):523-528

2. Schneider I (2004) Calcium pyrophosphate dihydrate-crystal induced arthropathy. Z Rheumatol 63(1):10-21

3. Dufauret-Lombard C, Vergne-Salle P, Simon A, Bonnet C, Treves R, Bertin P (2010) Ultrasonography in chondrocalcinosis. Joint Bone Spine 77(3):21822

4. McCarty DJ, Kohn NN, Faires JS (1962) The significance of calcium phosphate crystals in the synovial fluid of arthritis patients: the pseudogout syndrome, Clinical aspects. Ann Intern Med 56:711-737

5. Markel SF, Hart WR (1982) Arthropathy in calcium pyrophosphate crystal deposition disease. Pathologic study of 12 cases. Arch Pathol Lab Med 106: 529-533

6. Naqvi AH, Abraham JL, Kellman RM (2008) Calcium pyrophosphate dehydrate crystal deposition disease (CPPD) pseudogout of the tempromandibular joint - FNA finding and microanalysis. Cyto J 5:8

7. EL-Gabalawy HS. (2009) Synovial fluid analysis, synovial biopsy, and synovial pathology. In: Gary SF, Ralph CB, Sherine EG, lain BM, James RO (eds) Kelley's Textbook of Rheumatology, 9th edn. Elsevier, Philadelphia, pp 753769

8. Terkeltaub R (2013) Calcium crystal disease: calcium pyrophosphate dihydrate and basic calcium phosphate. In: Gary SF, Ralph CB, Sherine EG, lain BM, James RO (eds) Kelley's Textbook of Rheumatology, 9th edn. Elsevier, Philadelphia, pp 1576-1596

9. Filippucci E, Scirè CA, Delle Sedie A, lagnocco A, Riente L, Meenagh G et al (2010) Ultrasound imaging for the rheumatologist. Sonographic assessment of the knee in patients with gout and calcium pyrophosphate deposition disease. Clin Exp Rheumatol 28:2-5

10. Rosenthal AK. Crystal arthropathies, Calcium pyrophospate dihydrate disease. In Oxford Textbook of Rheumatology, 3rd ed. Isenberg D A, Maddison P J, Woo P, Glass D, and Breedveld F C. Oxford University Press 2004;1126-1131.

11. Assaker R, Louis E, Boutry N, Bera-Louville A, Paul LJ (2001) Foramen magnum syndrome secondary to calcium pyrophosphate crystal deposition in the transverse ligament of atlas. Spine 26:1396-1400

12. McCarty DJ (1994) Crystals and arthritis. Dis Month 6:255

13. Zhang W, Doherty M, Bardin T, Barskova V, Guerne PA, Jansen TL et al (2011) European League Against Rheumatism recommendations for calcium pyrophosphate deposition. Part I: terminology and diagnosis. Ann Rheum Dis 70(4):563-570 
14. Frediani B, Filippou G, Falsetti P, Lorenzini S, Baldi F, Acciai C et al (2005) Diagnosis of calcium pyrophosphate dihydrate crystal deposition disease: ultrasonographic criteria proposed. Ann Rheum Dis 64(4):638-640

15. Rosenthal AK, Ryan LM (2001) Calcium pyrophosphate crystal deposition disease; pseudogout; articular chondrocalcinosis. In: Koopman WJ (ed) Arthritis and Allied Conditions, 14th edn. Lea and Febiger, Philadelphia, pp 2348-2371

16. Bencardio JT, Hassankhani A (2003) Calcium pyrophosphate dihydrate crystal deposition disease. Semin Musculoskelet Radiol 7(3):175-185

17. MacMullen P, McCarthy G (2012) Treatment and management of pseudogout: insights for the clinician. Ther Adv Musculoskel Dis 54(11): 3508-3512

18. Tarkeltaub R (2012) Imaging joints for calcium pyrophosphate crystal. deposition: a knock to the knees. Arthritis Res Ther. 2830:40

19. Ellabban AS, Kamel SR, Abo Omar HAS, El-Sherif AMH, Abdel-Magied RA (2012) Ultrasonographic diagnosis of articular chondrocalcinosis. Rheumatol Int 32(12):3863-3868

20. Salaffi F, Carotti M, Guglielmi G, Passarini G, Grassi W (2008) The crowned dens syndrome as a cause of neck pain: clinical and computed tomography study in patients with calcium pyrophosphate dihydrate deposition disease. Clin Exp Rheumatol 26:1040-1046

21. Sekijima Y, Yoshida T, Ikeda S (2010) CPPD crystal deposition disease of the cervical spine: a common cause of acute neck pain encountered in the neurology department. J Neurol Sci. 296(1-2):79-82

22. Finckh A, Linthoudt DV, Duvoisin B, Ph B, Gerster J (2004) The cervical spine in calcium pyrophosphate dihydrate deposition disease. A prevalent casecontrol study. J Rheumatol (3):545-549

23. Gruber HE, Norton HJ, Sun Y, Hanley EN (2007) Crystal deposits in the human intervertebral disc: implications for disc degeneration. Spine J 7:444450

24. Berlemann U, Gries NC, Moore, Fraser RD, Vernon-Roberts B (1998) Calcium pyrophosphate dihydrate deposition in degenerate lumbar discs. Eur Spine J 1:45-49

25. Foldes K (2002) Knee chondrocalcinosis: An ultrasonographic study of the hyaline cartilage. J Clin Imaging 26:194-196

26. Filippou G, Frediani B, Gallo A, Menza L, Falsetti P, Baldi F et al (2007) A "new" technique for the diagnosis of chondrocalcinosis of the knee: sensitivity and specificity of high-frequency ultrasonography. Ann Rheum Dis 66:1126-1128

\section{Publisher's Note}

Springer Nature remains neutral with regard to jurisdictional claims in published maps and institutional affiliations.

\section{Submit your manuscript to a SpringerOpen ${ }^{\circ}$ journal and benefit from:}

- Convenient online submission

- Rigorous peer review

- Open access: articles freely available online

- High visibility within the field

- Retaining the copyright to your article

Submit your next manuscript at $\boldsymbol{\nabla}$ springeropen.com 